\title{
Quantifying Rooftop Rainwater Harvest Potential: Case of Mbeya University of Science and Technology in Mbeya Tanzania
}

\author{
Zacharia Katambara \\ Department of Civil Engineering, Mbeya University of Science and Technology, Mbeya, Tanzania \\ Email: zkatambara1@gmail.com, zacharia.katambara@mist.ac.tz
}

Received July 21, 2013; revised August 21, 2013; accepted August 28, 2013

Copyright (c) 2013 Zacharia Katambara. This is an open access article distributed under the Creative Commons Attribution License, which permits unrestricted use, distribution, and reproduction in any medium, provided the original work is properly cited.

\begin{abstract}
The advantages that the rooftop rainwater harvesting system has as a source of water supply have been examined. The observed daily rainfall records of 10 years and the current total roof area of the facilities at Mbeya University of Science and Technology as the catchment area were used. Using a water balance model to determine the suitable water use that will cover $100 \%$ of the time, the model indicated that for the current roof area a water supply of 120 lts per day can be met when a storage tank whose capacity is $13.5 \mathrm{~m}^{3}$ is installed. When values higher than $120 \mathrm{l} /$ day are simulated, a tank of higher capacity is required to meet the water demand. The study recommends on the necessity of installing rooftop rainwater harvesting system so as to increase the water supply reliability and reduction of cost. The selection of a suitable storage tank capacity should take into consideration the future development plans so as to reduce the construction cost of new storage tank.
\end{abstract}

Keywords: Rooftop Rainwater Harvesting Systems; Consumption Rate; Tank Capacity; First Flash

\section{Introduction}

In areas where the water supply systems are functioning, majority of the existing buildings and other facilities as well as the development plans have been observed to place less emphasis on the incorporation of rooftop rainwater harvesting systems (RRWHS). This has been substantially attributed to budget constraints [1] as well as to the limited knowledge on the potential of the harvested rainwater. Several studies related to rainwater harvesting have been done. The amount of water from the central water supply authorities may be reduced by an average of $69 \%$ when rainwater is used [2-5]. On the other hand, the quality of harvested rainwater is influenced by the type of roofing materials. It has been noted that metal roofing materials have lower concentrations of fecal indicator bacteria than other roofing materials [6]. During the onset rainfall, the samples of the collected rainfall indicate that pollutants concentration is high in the first liter but decrease substantially in the subsequent samples [7]. A study done at the University of Dar es Salaam in Tanzania indicated that the communities raised objections on the taste of the harvest rainwater [8]. To improve the quality of the harvested water, incorporation of first flash units in the RRWHS to divert first rainfall from entering the water system is imperative. Globally, Chiu et al. [9] found that the harvested water has the potential to ease water shortage problems. In addition to it being a source of water, rainwater harvesting practices when implemented on the upstream a catchment; it substantially reduces the frequency and the size of the peak flows that have the potential to cause flooding downstream. It is against this background that this study attempts to determine the potential yield of the total rooftop area of the buildings at Mbeya University of Science and Technology (MUST) in Tanzania.

\section{Description of the Study Area and Data Available}

\subsection{Location of Mbeya University of Science and Technology}

Within Mbeya Region of Tanzania, Mbeya University of Science and Technology is located on the higher altitude of unplanned settlement of Inyala and Ikuti areas that are characterised by inadequate provision of surface water drainage. Although the surface runoff generated has to flow through these areas before joining River Nzovwe, the surface runoff have been noticed to erode the un- 
paved road and causing the development of the undesirable potholes which partly impairs the usability of the road. A recent flood event that occurred in 2011 caused loss of property and left some families homeless. On the other hand, MUST own an area of more than 2000 ha and only a very small potion of the total area have been developed. The demand for higher education that positions MUST as a niche to positively contribute to government initiatives on "Big Results Now" will lead to the production of competent techno-entrepreneurs. In this respect, plans that respond to the highly needed scientific and technological innovations in a more diversified manner are underway at MUST. As such, in few years to come, more facilities will be erected and further increase the roof area. Currently, the total roof area is 22,906 $\mathrm{m}^{2}$ and it includes the area covered by office blocks, hostel building, workshop and residential houses. With such an area, limited knowledge exists with respect to the potential yield and is the subject of this study.

\subsection{Rainfall Data}

Daily rainfall data used in the study was obtained from Uyole Meteorological station spanning from the year 2000 to 2009. The data indicates that the study area receives uni-modal rainfall which starts from October through May and most of the rainfall is received during the months of January and March. The annual rainfall received ranges from $986 \mathrm{~mm}$ to $2200 \mathrm{~mm}$.

\section{Methodology}

In order to ensure that the RRWHS achieves its goals, two issues need to be known and they include the design as well as the operation consideration. The design considerations are the rooftop catchment area A and tank volume $\mathrm{V}$ which is tank capacity. The operation consideration includes the demand and the target period of supply. Generally, the amount of rainfall which reaches the storage tank is always less than amount of rainfall received. The deference result to some of the water being used to wet the roof surface area. The amount of rainfall recorded is multiplied by a factor $\beta$ to account for the loss and a value of $90 \%$ was considered as suitable. During dry periods, the roof normally collects dust. This is washed away by the first rainfalls. So, the first rains should not enter the tank. Therefore, a first flash amount represented by $\eta$ is subtracted for the recorded rainfall and a value of $1.0 \mathrm{~mm}$ was considered [10]. The amount of water entering the tank at time step $t$ is given by:

$$
P_{t}=\beta\left(P_{R t}-\eta\right)
$$

where $P_{R t}$ is the actual rainfall and $P_{t}$ is the portion of the rainfall which reaches the storage tank. The amount of water at any time, $t+1$ in the tanks is given by:

$$
V_{t+1}= \begin{cases}V_{t}+P_{t}-D_{t} & \text { for } V_{t}+P_{t}-D_{t} \leq V_{c} \\ 0 & \text { for } V_{t}+P_{t}-D_{t}<0 \\ V_{c}=V_{t}+P_{t}-D_{t}-S p_{t} & \text { for } V_{t}+P_{t} \geq V\end{cases}
$$

where $V_{c}$ is the storage capacity of the tank, $S p_{t}$ is the spill, $D_{t}$ is the demand, $V_{t}$ and $V_{t+1}$ is the volume of water in the tank at time step $t$ and $t+1$ respectively. The coverage period of supply is given as:

$$
E=\frac{n}{N} \times 100
$$

where $E$ is the target period of supply, $n$ is the number of days which the demand was met and $N$ is the number days for the design period.

\section{Results and Discussion}

Figure 1 shows the coverage and number of water shortage days per year against the water consumption per day. Although higher values of water demand can be used, the study considered a maximum daily consumption of $1000 \mathrm{l} /$ day and was considered to be adequate for current roof area. The simulations indicated that for a consumption rate of $120 \mathrm{l} /$ day water can be available for the whole year when a storage tank of $13.5 \mathrm{~m}^{3}$ is constructed. When the consumption is increased the coverage decreased gradually. Water can be available for $60 \%$ of the time when the demand is $1000 \mathrm{l} /$ day and the corresponding number of days when water is not available is 140 days/year. Figure 2 shows the storage tank capacity against water consumption per day. For storage of 118 $\mathrm{m}^{3}$ the consumption rate is $1000 \mathrm{l} /$ day and it decreased with decrease in water consumption. Considering Equation (1), the first flash is subtracted every time when the rainfall occurs since it assumes that the surface becomes dirty after the rain event. This is not the case for areas where the roof top becomes dirty because of dust which is not available when the ground surface is wet. To improve the water consumption, the splash value should

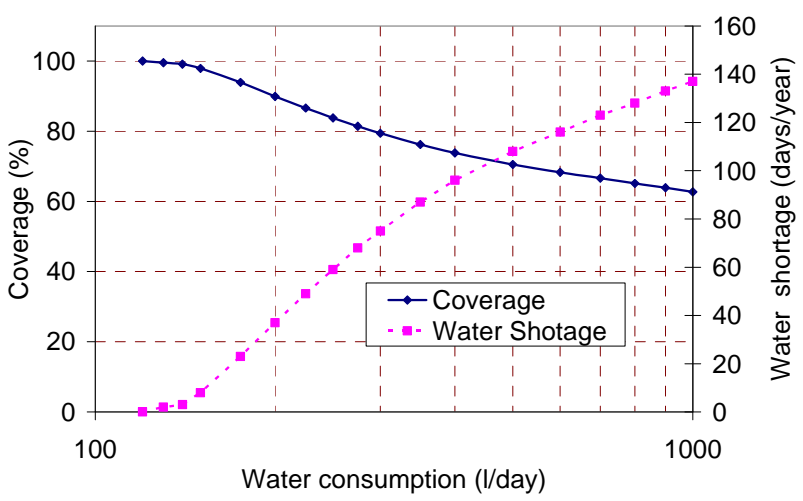

Figure 1. Coverage and number of water shortage days per year against the water consumption per days. 


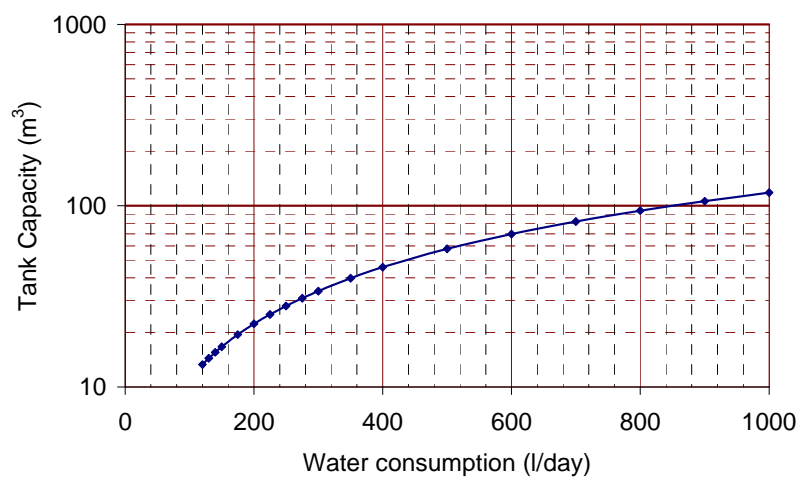

Figure 1. Water consumption against tank capacity.

reflect the soil moisture and therefore calls for Equation (1) to be linked to soil moisture balance routine which indicates the appropriate days to apply the splash value. In a situation where the harvested rainwater is intended for irrigation, the splash value to be used is zero.

\section{Conclusion and Recommendation}

The potential rooftop rainwater harvesting has been evaluated for the Mbeya University of Science and Technology using the current roof area and 10 years recorded daily rainfall from Uyole Meteorological Station. The water consumption rate increased with decrease of coverage and the storage tank capacity increased with increase in water consumption rate. For the implementation of the rainwater harvesting system, future development plans need to be taken into consideration so as to reduce the cost of constructing a storage tank.

\section{Acknowledgements}

The author acknowledges support received from the management of Mbeya University of Science and Technology and comments from the reviewers are also acknowledged.

\section{REFERENCES}

[1] D. Rutashobya, "Experiences Gained in the Development of Rainwater Catchment in Tanzania,” Proceeding of the 9th International Conference on Rainwater Catchment Systems, Petrolina, 1999.

[2] F. A. Abdulla and A. W. Al-Shareef, "Roof Rainwater Harvesting Systems for Household Water Supply in Jordan,” Desalination, Vol. 243, No. 1-3, 2009, pp. 195-207. http://dx.doi.org/10.1016/j.desal.2008.05.013

[3] L. Handia, J. M. Tembo and C. Mwiindwa, "Potential of Rainwater Harvesting in Urban Zambia,” Physics and Chemistry of the Earth, Parts $A / B / C$, Vol. 28, No. 20-27, 2003, pp. 893-896.

[4] B. Mati, et al., "Mapping the Potential of Rainwater Harvesting Technologies in Africa," 2007.

[5] M. Sturm, et al., "Rainwater Harvesting as an Alternative Water Resource in Rural Sites in Central Northern Namibia," Physics and Chemistry of the Earth, Parts $A / B / C$, Vol. 34, No. 13-16, 2009., pp. 776-785. http://dx.doi.org/10.1016/j.pce.2009.07.004

[6] C. B. Mendez, et al., "The Effect of Roofing Material on the Quality of Harvested Rainwater," Water Research, Vol. 45, No. 5, 2011, pp. 2049-2059. http://dx.doi.org/10.1016/j.watres.2010.12.015

[7] M. I. Yaziz, et al., "Variations in Rainwater Quality from Roof Catchments,” Water Research, Vol. 23, No. 6, 1989, pp. 761-765. http://dx.doi.org/10.1016/0043-1354(89)90211-X

[8] A. Mayo and D. Mashauri, "Rainwater Harvesting for Domestic Use in Tanzania: A Case Study: University of Dar es Salaam Staff Houses,” Water International, Vol. 16, No. 1, 1991, pp. 2-8. http://dx.doi.org/10.1080/02508069108686093

[9] Y.-R. Chiu, C.-H. Liaw and L.-C. Chen, “Optimizing Rainwater Harvesting Systems as an Innovative Approach to Saving Energy in Hilly Communities,” Renewable Energy, Vol. 34, No. 3, 2009, pp. 492-498. http://dx.doi.org/10.1016/j.renene.2008.06.016

[10] J.-M. Mwenge Kahinda, A. E. Taigbenu and J. R. Boroto, "Domestic Rainwater Harvesting to Improve Water Supply in Rural South Africa," Physics and Chemistry of the Earth, Parts $A / B / C$, Vol. 32, No. 15-18, 2007, pp. 10501057. http://dx.doi.org/10.1016/j.pce.2007.07.007 